\title{
CRIATIVIDADE: A HABILIDADE NECESSÁRIA AOS PROFISSIONAIS NESTE SÉCULO
}

\author{
CREATIVIDAD: LA HABILIDAD NECESARIA PARA LOS PROFESIONALES DE \\ ESTE SIGLO
}

\section{CREATIVITY: THE NECESSARY SKILL FOR PROFESSIONALS IN THIS CENTURY}

\author{
Maria Angela Barbato CARNEIRO ${ }^{1}$ \\ Neide de Aquino NOFFS ${ }^{2}$
}

RESUMO: O momento atual da humanidade tem se caracterizado por inúmeras mudanças sociais, econômicas e políticas que se refletem na educação. Fruto desse processo, ela deve estar alinhada à nova ordem mundial sem, contudo, perder de vista as funções; reflexiva, cooperativa, comunicativa e criativa. Nesse sentido, este trabalho tem como objetivo principal discutir o conceito de criatividade e a sua relevância no desenvolvimento das habilidades fundamentais na formação de docentes, buscando transformá-los em sujeitos críticos e capazes de solucionar rapidamente os problemas enfrentados no mundo atual. Dessa feita, a formação de profissionais da educação deve desenvolver a capacidade criativa de modo que eles se tornem sujeitos ativos, no processo de transformação social. Trata-se de um estudo teórico que se propõe a oferecer algumas sugestões para a docência de modo a estimular, sobretudo na universidade, o processo criativo.

PALAVRAS-CHAVE: Educação. Criatividade. Habilidade docente.

RESUMEN: El momento actual de la humanidad se ha caracterizado por numerosos cambios sociales, económicos y políticos que se reflejan en la educación. El resultado de este proceso debe ser alineado con el nuevo orden mundial, sin embargo, perder de vista las funciones; reflexivo, cooperativo, creativo y comunicativo. En este sentido, este trabajo tiene como objetivo principal discutir el concepto de creatividad y su importancia en el desarrollo de habilidades fundamentales en la formación de maestros, que buscan para convertirlos en sujetos críticos y capaces de resolver rápidamente los problemas que enfrenta el mundo hoy. Esto hizo la formación de profesionales de la educación debe desarrollar la capacidad creativa para que sean sujetos activos en el proceso de transformación social. Es un estudio teórico que pretende ofrecer algunas sugerencias para la enseñanza con el fin de estimular, sobre todo en la Universidad, el proceso creativo.

\footnotetext{
${ }^{1}$ Pontifícia Universidade Católica de São Paulo (PUC/SP), São Paulo - SP - Brasil. Professora Titular no Departamento de Fundamentos da Educação e Coordenadora do Núcleo de Cultura e Pesquisas do Brincar. Doutorado em Ciências da Comunicação (USP). ORCID: https://orcid.org/0000-0002-5039-9326. E-mail: mabarbato@gmail.com

2 Pontifícia Universidade Católica de São Paulo (PUC/SP), São Paulo - SP - Brasil. Professora Titular no Departamento de Formação Docente, Gestão e Tecnologias, Presidente vitalícia da ABPp, Assessora Institucional na Rede Municipal de Ensino e Coordenadora Geral da Comissão de Regulamentação e Formação do Psicopedagogo no Brasil junto à ABPp. Doutorado em Educação (USP). ORCID: https://orcid.org/0000-00031700-7682. E-mail: nnoffs@terra.com.br
}

RIAEE - Revista Ibero-Americana de Estudos em Educação, Araraquara, v. 15, n. esp. 4, p. 2741-2755, dez., 2020. e-ISSN: 1982-5587 
PALABRAS-CLAVE: Educación. Creatividad. Habilidad docente.

ABSTRACT: The present moment of humanity has been characterized by countless social, economic and political changes that are reflected in education. As a result of this process, it must be aligned with the new world order without, however, losing sight of the functions; reflective, cooperative, communicative and creative. In this sense, this work has as main objective to discuss the concept of creativity and its relevance in the development of the fundamental skills in the formation of teachers, seeking to transform them into critical subjects capable of quickly solving the problems faced in the current world. This way, the formation of education professionals must develop their creative capacity so that they become active subjects in the process of social transformation. This is a theoretical study that proposes to offer some suggestions for teaching in order to stimulate the creative process, especially at university.

KEYWORDS: Education. Creativity. Teaching ability.

\section{Introdução}

Este trabalho é resultado da observação do desempenho, enquanto docente, formando profissionais na área da educação infantil.

A prática tem mostrado que o século XXI passou por inúmeras transformações sociais, econômicas, culturais e políticas, determinadas por aquilo que Arendt $(1996)^{3}$ denominou a crise da modernidade. Tais mudanças têm modificado a ordem mundial e exigido, por parte da educação, outras habilidades diferentes daquelas praticadas nos séculos anteriores.

Do ponto de vista social tem aumentado a pobreza mundial e com ela os conflitos entre diversos grupos em diferentes países. O crescimento da população carente, entre outros fatores, não é um fato único, mas decorre de outros elementos como, por exemplo, o aumento demográfico e a expansão do modo capitalista de produção que transformou as economias locais em economia global.

No caso do primeiro há de se considerar, em todos os continentes, o grande fluxo populacional que migrou para os centros urbanos em busca de melhores condições de vida e de trabalho, porém sem nenhuma formação, provocando o êxodo no campo e um desemprego estrutural nas cidades. No bojo desse processo aumentaram os problemas sociais decorrentes da ausência de infraestrutura e de políticas públicas.

No caso do segundo, com a abertura dos mercados internacionais e o aumento do modo capitalista de produção, cresceu a miséria mundial, devido aos baixos salários, à substituição

${ }^{3}$ Segundo Arendt a crise da modernidade caracteriza-se pelas mudanças na autoridade na cultura e na autoridade.

RIAEE - Revista Ibero-Americana de Estudos em Educação, Araraquara, v. 15, n. esp. 4, p. 2741-2755, dez., 2020. e-ISSN: 1982-5587 
da mão de obra humana pelas novas tecnologias de produção, ao desenvolvimento dos sistemas de comunicação e informação e, especialmente, pela diminuição da participação do Estado na área dos direitos sociais, fazendo com que eles ficassem a cargo do setor privado.

Se, até a metade do século passado o modelo político liberal foi dominante, colocando a educação como um dos direitos do cidadão, o neoliberalismo crescente a partir dos anos 70, passou a abordar a escola no âmbito do mercado, pois uma vez que o Estado se ausentou de tal responsabilidade, permitiu que a empresa privada assumisse esse papel, deixando um grande contingente da população fora da escola. Esse descompromisso, porém, não se refere apenas à privatização da educação, mas à associação entre ela e as demandas do mercado de trabalho e das multinacionais, impedindo que um número cada vez maior de pessoas tenha acesso a esse bem.

Neste século, observa-se uma interligação crescente das economias mundiais e das nações industrializadas, desprovidas de conteúdo político democrático, a partir do livre comércio. Tal processo resulta da combinação de alianças estratégias e de cooperação, da organização de agentes econômicos em redes e do desenvolvimento das novas tecnologias da comunicação e da informação. Esses fatores acabaram por modificar as culturas locais e singulares, transformando-as em culturas globais. Logo, as peculiaridades de cada povo têm se transformado em universalidades e a escolarização tem se voltado para o atendimento dos interesses empresariais internacionais, contribuindo para o crescimento da miséria mundial e para a exclusão de crianças e jovens da educação.

De acordo com Marrach (1996), o processo neoliberal, não alterou a estrutura piramidal da sociedade, pelo contrário, piorou o modelo de distribuição de renda da população, aumentando ainda mais os problemas sociais, econômicos, culturais e políticos já existentes nos diversos países e, consequentemente, educacionais.

Nesse âmbito "a globalização pode ser definida pela circulação de fluxos e pelo desenvolvimento correlativo de empresas multinacionais. Essas existiam antes da globalização, mas se tornaram ainda mais potentes com a globalização e o recuo do Estado" (CHARLOT, 2013.p. 47).

Isso demonstra que o processo de mundialização cresceu mais com a diminuição do poder do Estado e da sua responsabilidade na área social, deixando tal incumbência a cargo do setor privado, de tal forma que acabam prevalecendo as leis do mercado. Evidentemente que tais transformações afetaram os diferentes contextos e, dentro deles, a escola. 


\section{A sociedade da informação e as novas exigências na formação de profissionais}

A sociedade da informação, porém, exige uma mudança de paradigmas, priorizando o domínio de certas habilidades, dantes desnecessárias, fazendo com que a escolarização prepare o homem para o trabalho, de modo que haja mão de obra qualificada apta para competir no mercado interno e externo. Dessa forma a instituição tem estimulado a competição além de ter se configurado como um mercado para produtos da indústria cultural e da informática, funcionando de forma similar a ele.

Apesar da globalização ser um processo econômico, no que tange à cultura, suas consequências se espalham por outras áreas, provocando o encontro entre os grupos, a divulgação de novas formas de expressão e de comunicação, o crescimento da mídia mundial, a difusão de produtos culturais e a generalização da língua inglesa como idioma internacional.

A educação reflete as influências internacionais de modo que a escola se viu obrigada a mudar em função das novas demandas do mercado, tendo que desenvolver outras habilidades tais como, por exemplo, conhecimento, reflexão, competência, cooperação e criatividade.

Exige-se, portanto, um novo homem para um mundo novo no qual o aprendizado deve ser contínuo.

Aparentemente, a escola se abriu para "toda" a população nos últimos 40 (quarenta) anos e, agora, deveria se atendê-la com qualidade, mas a educação mostra-se, ainda, como um grande desafio, porque se mantem como reprodutora de princípios doutrinários, onde as classes desfavorecidas permanecem excluídas, mais ainda, sem direito à receber um ensino de qualidade.

Entretanto, no mercado de trabalho embora se atribua um papel fundamental à escolarização, nem sempre questiona a sua qualidade em geral até porque, na maior parte das vezes, ela não é um meio de reflexão e de transformação dos princípios doutrinários vigentes, reforçando, assim, ainda mais, o controle político e ideológico. A tais fatores observa-se que em vários países desenvolvidos houve, nos últimos anos, um crescimento de grupos políticos com ideologias fascistas e antidemocráticas, dominado, por trás de tudo isso, pelo poder do capital.

A par dessas transformações salienta-se, também, que na sociedade do século XXI não existem mais verdades absolutas, mas realidades em perspectivas, fazendo-se necessária a atualização contínua dos conhecimentos científicos devido, sobretudo, à evolução dos meios de comunicação, que passaram a exigir aprendizagens básicas que possibilitem uma relação permanente entre a cultura local e a global. 
No interior desse contexto a educação busca atender às exigências do mercado internacional, até mesmo porque seus interesses são adotados pelo próprio Estado, enquanto poder público. Além disso, as novas lógicas exigem trabalhadores e consumidores mais formados, pois de acordo com Charlot (2013) não se trata apenas de desenvolver competências técnicas, mas melhorar o nível da formação básica da população.

\section{A educação e suas novas demandas}

Tal demanda passa pela educação, porém não alienada, mas consciente e refletida. Para ser oferecida com qualidade ela necessita de conhecimento, de compromisso, de cooperação e de criatividade, de tal sorte que o ser humano possa ser sujeito e, não objeto, da sociedade em que vive.

Dentro dessa nova realidade é que se deve pensar a escola e a educação, dentro do contexto atual de modo que ele forneça os elementos necessários para que o ser humano possa viver dentro do seu tempo, contribuindo com as transformações adequadas para a sociedade na qual se insere. Portanto, a instituição deve estar preparada para o grande desafio, que consiste em oferecer um ensino de qualidade a toda a população, de modo que a educação cumpra a sua função humanizadora e transformadora, onde a reflexão e a ação sejam constituintes inseparáveis da práxis.

Segundo Freire (1982), o ser humano é inacabado e se constrói continuamente, tanto do ponto de vista filogenético, quanto ontogenético, não podendo ignorar que tem uma história enquanto sujeito singular que é. Tal afirmação leva o pensador a explicitar sobre a função transformadora do processo educativo, desde que ela seja consciente, crítica e comprometida.

Infelizmente, porém, atingida pela chamada crise mundial, a escola brasileira, nos últimos 40 anos se abriu, aparentemente, para toda a população, permitindo que um contingente maior de pessoas a ela tivesse acesso. Porém, um dos grandes entraves observados é que ela continuou elitista, não alterando nem a sua estrutura, nem o seu funcionamento, atuando de forma bastante similar ao momento da sua origem, de modo que continuou provocando o fracasso escolar, a exclusão e a desigualdade social, além de não atender às exigências do mercado.

À primeira vista parece que as transformações sociais não atingem a educação e, particularmente, a escola, no entanto, elas fazem parte de um contexto mais amplo no qual se integram e estão intrinsecamente inter-relacionadas, através influências contínuas. 
Nessa perspectiva concordamos com Charlot (op.cit.), para quem existem quatro grandes desafios a serem enfrentados pela escola na sociedade contemporânea, aumentar o nível de formação da população como um todo, melhorar a qualidade do trabalho realizado, encarar os novos desafios educativos e culturais e redefinir os conteúdos escolares.

Tais desafios passam pela adoção de políticas públicas, pelo financiamento necessário às pesquisas, pela criação de infraestrutura adequada, pela capacitação, valorização e remuneração do magistério, fatores esses que no Brasil, parecem, há muito tempo, ter sido esquecidos.

Dentre os principais obstáculos arrolados merece atenção especial a formação docente, visto que a realidade vivida pela maioria dos professores é bastante contraditória, porque envolve por um lado uma perspectiva de educar para o presente, porém, por outro, não se pode perder de vista o passado e o futuro. O primeiro, por ajudar a entender e a alicerçar alguns conhecimentos importantes e, o futuro, por projetar novos objetivos que redundem em uma sociedade mais justa, menos competitiva e mais igualitária.

Logo, como muito bem explicitou Delors (1996) em uma de suas obras, que compete à educação, oferecer às crianças e aos adultos os conhecimentos básicos, que permitam identificar as rápidas mudanças da sociedade contemporânea., supondo, portanto, novos conteúdos e habilidades e, principalmente, a capacidade de refletir sobre uma gama de informações a fim de entendê-las melhor dentro de seus respectivos contextos sociais e políticos.

É nesse âmbito que, após anos de docência, realizamos este trabalho, refletindo sobre alguns elementos, a partir da experiência que podem contribuir para melhorar a escola e, de modo especial, a formação dos docentes, destacando-se os que atuarão junto às crianças pequenas.

Tal preferência se deve ao fato de que as pesquisas recentes sobre a psicologia, a medicina, a sociologia e a educação, entre outras ciências, têm apontado para a relevância dos cinco primeiros anos de vida, portanto, atuar com os pequenos supõe o trabalho de um profissional bem formado.

Na formação docente merecerá atenção especial o desenvolvimento da criatividade. A escolha incidiu sobre tal área, por dois motivos. O primeiro pelo fato de que ela se constitui em um dos elementos básicos para a prática reflexiva. O segundo porque dada a sua desvalorização precisa ser, urgentemente, repensada diante das habilidades exigidas para o homem do século XXI. 
Trata-se, portanto, de uma discussão teórica que permitirá estabelecer alguns pontos fundamentais para iluminar as práticas nas licenciaturas que formam profissionais para atuarem, principalmente, no âmbito da educação infantil.

A formação docente neste século se torna um processo muito complexo, considerandose a existência de várias contradições do contexto local e internacional, interfere na educação, exigindo que o profissional esteja preparado e, portanto, tenha conhecimento da realidade, compromisso com ela, atue cooperativamente e seja criativo para solucionar os múltiplos problemas enfrentados cotidianamente.

Na perspectiva do conhecimento, por exemplo, é fundamental que o docente detenha o conteúdo a ser trabalhado e, também, saiba refletir sobre ele, pois de acordo com Imbernón (2017), o conhecimento sempre é "heterodoxo, autônomo e heterônomo" ", na prática educativa. Portanto, ele é parte integrante do pensamento, porque é reflexivo e isso se espelha na da práxis. $^{5}$

No âmbito da docência o pensamento se associa ao conhecimento e à maneira de ensinálo. Contudo, essas duas condições não são suficientes, pois a elas se associa o compromisso do profissional com a sociedade em que se insere, exigindo, segundo Freire (op. Cit.), uma decisão lúcida e profunda de quem assume o processo educativo, no qual condição necessária para o ato comprometido é a relação dialógica estabelecida entre a reflexão e a ação que possibilita ter consciência da realidade. Assim, o compromisso do profissional deve envolver um engajamento com o contexto em que atua o que exige o exercício da cidadania e da solidariedade.

De acordo com o pensador, " não há homem sem mundo, nem mundo sem homem" portanto, " não pode haver reflexão e ação fora da realidade". ${ }^{6}$ É nesse sentido que se deve pensar a educação, pois não deve haver educador fora do contexto, porque só refletindo sobre ela é que será possível transformá-la.

O compromisso e o conhecimento são características fundamentais e complementares, no caso da docência, que devem vir acompanhados de um sentimento de que o fazer educativo transforma a realidade, ponto fulcral para melhorar a educação e o futuro da humanidade. Portanto, a formação docente deve considerá-lo em todas as suas nuances e perspectivas. Só, assim, será possível exercer responsavelmente a ação educativa.

${ }^{4}$ Palavras de Imbernón.

${ }^{5}$ Praxis está sendo utilizada neste trabalho de acordo com a visão freireana de educação, mostrando a relação existente no processo ação-reflexão- ação.

${ }^{6}$ Palavras de Freire.

RIAEE - Revista Ibero-Americana de Estudos em Educação, Araraquara, v. 15, n. esp. 4, p. 2741-2755, dez., 2020. e-ISSN: 1982-5587 
Às características apresentadas deve-se associar o valor da cooperação. Torna-se difícil trabalhar isoladamente, especialmente em um momento em que se multiplicam as informações em rede.

A exigência duma solidariedade à escala mundial supõe, por outro lado, que todos ultrapassem a tendência de se fecharem sobre si mesmos, de modo a abrir-se à compreensão dos outros, baseada no respeito pela diversidade. A responsabilidade da educação nessa matéria é, ao mesmo tempo, essencial e delicada na medida em que a noção de identidade se presta a uma dupla leitura: afirmar a diferença, descobrir os fundamentos da sua cultura, reforçar a solidariedade do grupo, podem constituir para qualquer pessoa, passos positivos e libertadores, mas quando mal compreendido este tipo de reivindicação contribui, igualmente, para tornar difíceis e, até mesmo impossíveis, o encontro e o diálogo com o outro (DELORS, 2003, p. 42).

Por tais razões nesse processo de globalização aliam-se à cooperação, outras habilidades que os docentes devem possuir tais como a comunicação e a criatividade.

Inicialmente é fundamental pensar na comunicação, pois, o destino de cada um de nós, na aldeia global, está circunscrito a uma escala mundial, pois com abertura de fronteiras econômicas estimuladas pelo livre comércio aumentou a interdependência planetária, o que têm provocado, rapidamente, o crescimento de problemas para os quais não estamos preparados para solucionar.

Juntamente com o livre comércio surgiram também os movimentos migratórios de pessoas para os países desenvolvidos ou para aqueles que apresentam um pouco mais de segurança econômica e política em busca de melhores condições de vida e de trabalho. Em todos os continentes tais movimentos vem crescendo e, diante de tal mobilidade, há necessidade de um acolhimento destinado aos migrantes e necessita, por parte da educação, tolerância, inclusão e respeito à diversidade.

Para Delors (2003), ajudar a transformar a interdependência real em solidariedade é uma importante tarefa da educação daí o valor de se compreender o mundo e o outro e, portanto, a necessidade de um profissional que atue cooperativamente. Isso implica no conhecimento melhor de si e das formas de relacionar-se com os demais, exigindo uma educação mais solidária e colaborativa, de modo que possam ser contemplados os conhecimentos e as culturas diferentes, factíveis através do estabelecimento de vínculos sociais, objetivando o desenvolvimento humano na sua dimensão social e ética.

Se os movimentos migratórios provocaram internacionalmente graves conflitos, eles poderão ser minimizados pela cooperação, através da educação de modo a evitar os problemas de exclusão, da miséria e das lutas. 
Outro elemento a se considerar do ponto de vista educacional é a comunicação, especialmente num momento em que os meios de informação se propagaram e se desenvolveram rapidamente. Cresce cotidianamente a penetração das novas tecnologias, facilitada pelo baixo custo de materiais e equipamentos, tornando-as cada vez mais acessíveis.

É verdade que a revolução tecnológica se tornou um fator imprescindível para a compreensão da modernidade, criando novas formas de relacionamento. Porém, se por um lado ela possibilita a expansão do conhecimento em uma esfera mundial e o rápido intercâmbio com pessoas de outras partes do planeta, por outro há uma tendência de cada ser humano fechar-se sobre si próprio e isolar-se, comprometendo os laços de solidariedade.

Há, ainda, outras questões que podem ser abordadas como o fato de que o uso das novas tecnologias tem aumentado as distâncias entre os países desenvolvidos e os países pobres, porque os primeiros têm condições de atualizar continuamente suas pesquisas na área. No entanto, contrariamente tal desenvolvimento poderia contribuir para melhorar as regiões mais afastadas e carentes do planeta. Essa realidade parece ser, ainda, uma utopia, pois os países desenvolvidos têm prosseguido cientificamente com o rápido avanço dos seus conhecimentos, enquanto os mais pobres e periféricos têm se limitado a receber informações, sem que haja uma verdadeiramente troca.

Hoje, as informações ocorrem em tempo real, porém não se trata apenas da comunicação através de equipamentos, mas a interpessoal que necessita de relações mais profundas entre os seres humanos.

A educação reflete essa realidade, por vezes, dentro de um mesmo país, porque há escolas e professores dotados de infraestrutura tecnológica e novos recursos de comunicação, enquanto há outras que funcionam, apenas com a saliva do docente, o giz e o apagador. As formas de comunicação utilizadas na escola, ainda, se restringem à oralidade e a escrita, como se a humanidade só tivesse dependido delas para garantir a cultura dos inúmeros grupos sociais.

Evidentemente, que há, também, um vácuo entre os conhecimentos trabalhados, as aprendizagens realizadas e as habilidades exigidas, aumentando ainda mais as distâncias entre as populações e, por conseguinte, entre alunos ricos e pobres.

Dentre as habilidades necessárias para a vida humana e que devem ser tratadas pelas escolas está a criatividade, porque é um dos fatores responsáveis pela reflexão.

Ela será, portanto, objeto principal de estudo neste trabalho. Porém não se trata de um assunto simples a ser discutido, porque, tanto a sociedade, quanto a escola parecem desvalorizála. 


\section{Criatividade uma habilidade necessária neste século}

$\mathrm{O}$ ato de criar está intimamente ligado à liberdade de expressão e à utilização das diversas linguagens pelo ser humano. Porém, há muito tempo a sociedade e a educação tem valorizado apenas a linguagem oral e a escrita, deixando as demais em um segundo plano. Por isso tem razão Charlot (2013), ao afirmar que a instituição tende a ensinar o que pode ser dito através de palavras e negligenciar, desprezar e, às vezes até combater, o que envolve o corpo e a sensibilidade.

O caminho para a formação do homem centrado em seu mundo interior e exterior se dá por meio do saber, do sentir, do lúdico, do poético. Um caminho direcionado para o criativo, para a imaginação que favoreça ao homem a construção de seu mundo interior e exterior, diferenciando-o como indivíduo único que é.

É necessário que o educador pela sua percepção dos mundos interior e exterior, esteja em constante movimento de busca, pesquisa e estudo para sempre reinventar o necessário para a sua prática educacional, e que as relações existentes entre a escola e a comunidade, o professor e o aluno, a administração e os professores sejam relações reais com o mesmo propósito (STORI, 2003, p. 17).

Um professor descompromissado, não reflexivo e insensível será mais um elemento de reprodução dos valores elitistas e estagnação das transformações educacionais e sociais.

Se a criatividade é tão importante para contribuir na formação de um ser humano crítico e reflexivo, quais seriam os impedimentos para que ela seja estimulada? Por que, quando pequenas, as crianças são mais criativas e quando crescem perdem tal habilidade? Tal impedimento estaria ligado às práticas escolares? Essa discussão, portanto, toma como ponto de partida o conceito de criatividade, ideia esta que é bastante complexa.

Criar é, basicamente, formar. É poder dar forma a algo novo. Em qualquer que seja o campo de atividade, trata-se, nesse "novo, novas coerências que se estabelecem para a mente humana, fenômenos relacionados de modo novo e compreendidos em termos novos. $\mathrm{O}$ ato criador abrange, portanto, a capacidade de compreender; e esta, por sua vez, a de relacionar, ordenar, configurar, significar (OSTROWER, 1979, p. 9).

Segundo a autora, nos movemos entre formas, coisas que se configuram para nós. Cada ato nosso se relaciona com o nosso interior, se constituindo em uma maneira singular de focalizar e interpretar os fenômenos, dando a eles significados de modo que possamos compreender a vida. Tais processos são intuitivos, mas se tornam conscientes na medida em que lhe damos forma. Por essa razão, pode-se dizer que o homem é um ser formador porque é capaz de relacionar os eventos. 
Logo, o ato criativo toma por princípio a percepção consciente de si que surge a partir das necessidades concretas, que é um fator de realização pessoal e de transformação. Isso faz com que além de resolvermos situações imediatas somos capazes de antever problemas e solucioná-los. A criação, portanto, está relacionada à sensibilidade, por ligar o mundo exterior ao interior através da expressão simbólica.

Criatividade, portanto, pode ser considerada como uma função universal, que existe potencialmente em todo o ser humano e a sua ativação compete à educação através da utilização da sensibilização e das diferentes linguagens, pois elas consistem em manifestações da expressão criadora.

Criar é exprimir o que existe dentro de cada um de nós e resulta de um longo processo de elaboração. Tal habilidade depende da experiência de cada um e que se desenvolve de acordo com o contexto.

Vigotski (1998) mostrou em uma de suas obras que, o que chamamos de criação, é um complexo processo de gestação iniciado através da percepção externa e interna, servindo de base para a experiência de cada um.

Para ele a imaginação é extremamente complexa para ser estudada, constituindo um dos obstáculos principais para as investigações sobre criatividade. Aponta que tal habilidade depende de uma longa gestação, que o ser humano acumula para construir suas fantasias, envolvendo associações, dissociações, análises, sínteses, comparações...

Tais processos dependem da extração de características isoladas, que passam por transformações, rápidas e dinâmicas chegando muitas vezes ao exagero. Um dos fatores mais importantes para que ela se desenvolva é a necessidade de adaptar-se ao mundo que nos rodeia. Aquele que está perfeitamente adaptado ao seu contexto não poderia desejar, experimentar, descobrir e criar.

$\mathrm{O}$ ato criativo depende tanto de estímulos, quanto de imagens que sofrem influência das emoções, da experiência vivida e das necessidades de cada um. Logo, segundo o pesquisador, o inventor é sempre produto do seu meio e nenhum descobrimento aparece sem que sejam criadas condições materiais e psicológicas para isso. Toda obra criadora resulta, assim, de um processo histórico, onde cada nova forma se apoia na anterior. Quanto mais ricas são as experiências de cada um, maiores serão as chances que a pessoa terá para criar.

Não é possível haver criação a partir do nada, ela se assenta no conhecimento que se tem da realidade. Toda e qualquer fantasia se origina nos elementos extraídos do mundo real. Possui, portanto, numa relação direta com a riqueza de experiências vividas por cada um. Para criar é preciso relacionar a realidade com a fantasia. Uma vez acumuladas as experiências elas 
são amadurecidas e combinadas. Não há uma simples reprodução, mas rearranjos. Dessa forma a última se converte em uma ampliação da experiência, que permite ir muito além daquilo que se conhece. Muitas vezes a fantasia auxilia a conhecer a realidade.

Vale ressaltar, nesse processo, a influência do fator emocional, pois as representações acompanhadas de emoções se associam, resultando na combinação de imagens baseadas em sentimentos comuns, ainda que com representações divergentes, explicitando, assim, o vínculo recíproco entre imaginação e emoção. Logo todas as formas de imaginação criadora também dependem desse último fator.

A todos os elementos descritos anteriormente adiciona-se a representação de algo novo, que não existe na experiência humana e que nela acabam se materializando, voltando-se para a realidade. Pode-se dizer, portanto, que o ato criativo envolve a junção do sentimento e do pensamento e se estrutura sobre a tríplice relação entre fazer, perceber e sentir.

De acordo com Guilford e Löwefld (apud GLOTON; CLERO, 1976), são oito as características que evidenciam a criatividade: sensibilidade, receptividade, mobilidade, originalidade, análise, síntese e organização coerente: sensibilidade porque permite notar certas sutilezas, prever prejuízos, perceber emoções, descobrir necessidades e carências; receptividade que manifesta a abertura e a fluidez do pensamento; mobilidade que pressupõe a rápida adaptação a novas situações, favorecendo as mudanças; transformar e redimensionar a função de um objeto em outra de acordo com a necessidade do momento resultando na originalidade; abstrair certas capacidades fundamentais do objeto, oferecendo a possibilidade de perceber melhor as diferenças; sintetizar, permitindo a reunião de vários elementos formando novos conjuntos; e, finalmente, a organização coerente que consiste na capacidade de harmonizar os pensamentos.

Tais características devem ser cultivadas no ser humano, desde cedo de modo que eles possam se tornar criativos.

Pode-se dizer que quatro estágios do processo criativo, a preparação, quando a pessoa identifica as ideias; a incubação e quando elas permanecem no inconsciente para serem selecionadas; a iluminação quando o criador se torna consciente do ajustamento de todos os elementos e a verificação quando os detalhes finais são comprovados.

Assim, a criatividade envolve a educação do fazer, perceber e sentir para que o ser humano consiga manipular, compreender o meio que o cerca e relacionar-se com os meios simbólicos. Quanto mais a ela favorecer a prática dessa relação mais contribuirá para o desenvolvimento da criatividade. 
Porém, a educação e a criatividade na escola, parecem trafegar em direções opostas. Não há a valorização do ato criativo no processo de escolarização e as práticas pedagógicas, no Brasil, ainda são muito tradicionais, impedindo o uso de outras linguagens simbólicas.

De acordo com Charlot (2013), entre a estrutura organizacional tradicional e conservadora e um discurso construtivista, os professores tentam sobreviver, sem que haja um espaço/tempo real para que os alunos possam criar.

Isso se torna mais nítido no bojo do próprio processo de formação docente, porque a academia, ainda é predominantemente teórica, não havendo de fato um lugar para uma reflexão entre ela e a prática capaz de favorecer a existência de um clima liberal e aberto, que possibilite maior independência para os alunos se expressarem.

Nas licenciaturas tal realidade, ainda, parece ser pior, porque tem aumentado a perspectiva da pesquisa teórica, desvinculada da prática de determinadas habilidades capazes de favorecer a criatividade.

Habilidades artísticas e expressivas são vistas como meros passatempos e, muitas vezes, desprezadas como há um descaso pela infância.

A imaginação e a expressão criadoras são aptidões fundamentais para formar nos jovens, pois de acordo com Gloton e Clero (1997), elas ajudam os alunos a se armarem contra as alienações e a estarem atentos aos desvios das tecnologias e aos perigos das automatizações. Daí a importância da sua utilização na formação de pessoas livres, originais, com iniciativa e responsabilidade. E, para isso, elas precisam ser estimuladas.

Resta lembrar que, apesar das mudanças, a escola brasileira ainda é elitista e como a o ato criativo depende das experiências vividas pelos sujeitos, os alunos que possuem uma melhor condição econômica, geralmente têm vivências mais ricas o que, em tese, permite que tenham mais elementos para o desenvolvimento de tal habilidade.

Sendo altamente exclusiva, um grande contingente de alunos fica fora do processo educacional., portanto não têm a oportunidade de criar. Pior do que isso, os poucos que a ela têm acesso são impedidos de fazê-lo, porque são submetidos à uma educação tradicional, na qual os sentimentos, o fazer e o pensar não são relacionados e sim segmentados, dificultando o desenvolvimento da criatividade.

Em se tratando dos cursos de licenciatura a questão torna-se ainda mais séria, porque profissionais que não tiveram a oportunidade de experimentar certas habilidades, se sentirão inseguros desenvolverem tal habilidade ou para permitirem tais vivências aos seus alunos.

Trabalhar para a mudança significa transformarmos a nós mesmos, a partir das práticas através de experiências mais ricas, da utilização de inúmeras linguagens, além de maiores 
oportunidades de atividades favoreçam o conhecimento de novos espaços, o contato com outras formas de comunicação e de expressão unindo o pensar, o fazer e o sentir para, consequentemente, poderem criar.

\section{Reflexões finais}

A partir das reflexões realizadas ao longo deste trabalho sugerimos alguns passos para que a formação docente contribua para o desenvolvimento da criatividade. Por essa razão é importante pensar:

- $\quad$ que todas as pessoas são capazes de criar e que quanto mais experiências tiverem, mais ricas poderão ser suas representações simbólicas;

- $\quad$ que o ato criativo está intimamente relacionado ao ato reflexivo;

- $\quad$ que a utilização das diferentes linguagens enriquecerá as habilidades criativas;

- $\quad$ que a sala de aula é um ambiente de experimentação;

- $\quad$ que outros espaços, para além da escola, poderão contribuir para enriquecimento do conhecimento, a observação, a análise e reflexão do trabalho, valorizando habilidades criativas;

- $\quad$ que o professor deve ousar e permitir que seus alunos o façam também;

- $\quad$ que a oportunidade para criar depende de uma educação democrática e libertadora, em que a qualidade, não é um privilégio de poucos, mas, acima de tudo, um direito de todos.

Só assim será possível desenvolver o potencial criativo que existe em cada um de nós

\section{REFERÊNCIAS}

ARENDT, H. Entre el passado y el futuro: ocho ejercicios sobre la reflexión política. 1. ed. Barcelona: Península, 1996.

CHARLOT, B. Da relação com o saber às práticas. 1. ed. São Paulo: Cortez, 2013.

DELORS, J. Educação: um tesouro a descobrir. Lisboa: UNESCO/ ASA, 1996.

FREIRE, P. Educação e Mudança. Rio de Janeiro: Paz e Terra, 1982.

GLOTON, R.; CLERO, C. A actividade criadora da criança. Lisboa: Estampa, 1976.

IMBERNÓN, F. Ser docente em uma sociedade compleja: la difícil tarea de enseñar. São Paulo: Cortez/ Barcelona: Graó, 2017. 
MARRACH, S. Neoliberalismo e Educação. In: SILVA JR., C.; BUENO, M. S.;

GHIRALDELLI JR., P.; MARRACH, S. Infância, Educação e Neoliberalismo. São Paulo:

Cortez, 1996.

OSTROWER, F. Criatividade e processos de criação. 7. ed. Petrópolis: Vozes, 1987.

STORI, N. (Org.). O despertar da sensibilidade na educação. São Paulo: Instituto Presbiteriano Mackenzie: Cultura Acadêmica, 2003.

VIGOSTSKI, L. S. La imaginación y el arte en la infância. 4. ed. Akal: Madrid, 1998.

\section{Como referenciar este artigo}

CARNEIRO, M. A. B.; NOFFS, N. A. Criatividade: a habilidade necessária aos profissionais neste século. Revista Ibero-Americana de Estudos em Educação, Araraquara, v. 15, n. esp. 4, p. 2741-2755, dez., 2020. e-ISSN: 1982-5587. DOI: https://doi.org/10.21723/riaee.v15iesp4.14522

Submetido em: 10/09/2019

Revisões requeridas: 10/01/2020

Aprovado em: 30/04/2020

Publicado em: 01/12/2020 